\title{
THE SUPERSPECTRAL/HYPERSPATIAL WORLDVIEW-3 AS THE LINK BETWEEN SPACEBORNE HYPERSPECTRAL AND AIRBORNE HYPERSPATIAL SENSORS: THE CASE STUDY OF THE COMPLEX TROPICAL COAST
}

\author{
A. M. Collin ${ }^{1,2}, *$, M. Andel ${ }^{3}$, D. James ${ }^{4}$, J. Claudet ${ }^{5}$ \\ ${ }^{1}$ EPHE, PSL Université Paris, 35800 Dinard, France - antoine.collin@ephe.psl.eu \\ ${ }^{2}$ LabEx CORAIL, Moorea, French Polynesia \\ ${ }^{3}$ DigitalGlobe Foundation, 80234 Westminster, Colorado, USA - mark.andel@ digitalglobe.com \\ ${ }^{4}$ EPHE, PSL Université Paris, 35800 Dinard, France - dorothee.james@ephe.psl.eu \\ ${ }^{5}$ National Center for Scientific Research, PSL Université Paris, CRIOBE, 75005 Paris, France - joachim.claudet@ gmail.com
}

Commission III, WG III/4

KEY WORDS: WorldView-3, Hyperion, UAV, Superspectral, Coral Reefs, Moorea Island

\begin{abstract}
:
Earth observation of complex scenes, such as coastal fringes, is based on a plethora of optical sensors constrained by trade-offs between spatial, spectral, temporal and radiometric resolution. The spaceborne hyperspectral EO-1 Hyperion sensor (decommissioned in 2017) was able to acquire imagery with $10 \mathrm{~nm}$ spectral (220 bands) at $30 \mathrm{~m}$ spatial resolutions over $1424.5 \mathrm{~km}^{2}$ scenes. Conversely, the widespread unmanned airborne vehicle (UAV) hyperspatial DJI Mavic Pro camera can collect only naturalcoloured imagery of $100 \mathrm{~nm}$ spectral ( 3 bands) but at $0.1 \mathrm{~m}$ spatial resolution over $\sim 10 \mathrm{~km}^{2}$ scenes (with a single battery and calm meteo-marine conditions). The spaceborne WorldView-3 (WV3), featured by $60 \mathrm{~nm}$ spectral (16 bands) at $0.3 \mathrm{~m}$ spatial resolution (when pansharpened) over $1489.6 \mathrm{~km}^{2}$ scenes, has the capacity to bridge both sensors. This study aims at testing the spectral and spatial performances of the WV3 to discriminate 10 complex coastal classes, ranging from ocean, reefs and terrestrial vegetation in Moorea Island (French Polynesia). Our findings show that geometrically- and radiometrically-corrected 0.3-m 16-band WV3 bands competed with (30-m) 167-band Hyperion performance for classifying 10 coastal classes with 2-neuron artificial neural network modelling, while being able to segment objects seized by 0.1-m (3-band) UAV. Unifying superspectral and hyperspatial specificities, the WV3 also leverages hypertemporal resolution, that is to say 1-day temporal resolution, rivalling UAV's one.
\end{abstract}

\section{INTRODUCTION}

\subsection{Space-Spectrum-Time prism}

Coastal fringes host complex social-ecological systems facing global changes (sea-level rise and cyclone/storm intensification) and local pressures (unprecedented urbanization and ecosystem services degradation), thus requiring specific imagery sensors to be used. Ad hoc sensors are expected to capture coastal processes at the scale at which they act, that is to say over regional extents $\left(>1000 \mathrm{~km}^{2}\right)$ but with high spatial resolution (1 $\mathrm{m})$. Furthermore, sensors need to monitor a sufficient number of wavebands (> 10 bands) in order to disentangle spectrally-close coastal features, both within marine and terrestrial realms (Collin et al., 2013). In addition, the revisit or tasking time should be short enough to match the temporal frame in which coastal mechanisms occur, from days to months. However, a sensor delivering daily-to-monthly, hyperspectral images over regional extents at hyperspatial resolution does not exist, because of the hardware-based limitations. Judicious trade-offs between temporal, spectral and spatial resolutions have to be considered.

\subsection{Airborne and spaceborne hyperspectral platforms}

Even if handborne hyperspectral sensors provide very satisfactory results to retrieve inherent optical properties of the waters (Keller et al., 2018), the spatial coverage of coastal regional extents cannot be reached in a cost-effective manner, hindering monthly iterative acquisition.

Leveraging higher footprints, airborne hyperspectral sensors revealed great performance to classify coastal areas (Zhou et al., 2005), discriminate seagrasses (Peneva et al., 2008), or macroalgae (Dierssen et al., 2015). The integration of LiDAR data was also strongly validated for species distribution (Jones et al., 2010), agricultural and urban features (Tuia et al., 2016). Hyperspectral sensors mounted on unmanned airborne vehicle (UAV) recently showed suitable results for monitoring trees (Honkavaara et al., 2017). Covering regional extents at high spatial resolution, those surveys are good candidates for coastal issues, but the time-consuming mission planning and the costly aircraft pricing (Collin et al., 2014) make the temporal resolution too coarse to capture coastal processes.

Benefiting from a greater agility, concomitant with affordability, thus temporal resolution, spaceborne sensors have demonstrated their efficiency in estimating water quality (Brando and Dekker, 2003; Van Mol and Ruddick, 2004; Lucke et al., 2011), mapping coastal wetlands (Pengra et al., 2007), coral reefs (Kutser et al., 2006), soil parameters (Anne et al., 2014), and land cover/land use when fused with Sentinel-2 (Weinmann et al., 2018). Conciliating high spectral and temporal resolution with regional extents, the downside of those

\footnotetext{
* Corresponding author
} 
sensors (CHRIS, 19 bands at $17 \mathrm{~m}$ or 63 bands at $34 \mathrm{~m}$; Hyperion, 220 bands at $30 \mathrm{~m}$; HJ-1, 128 bands at $30 \mathrm{~m}$; $\mathrm{HICO}$ installed in the international space station, 128 bands at $90 \mathrm{~m}$ ) lies in their spatial resolution, mismatching coastal processes. Even PRISMA (220 bands), launched this year, or EnMAP (228 bands, Müller et al., 2010), will provide coastal images, relatively too coarse $(30 \mathrm{~m})$.

\subsection{Spaceborne superspectral and hyperspatial sensor}

In parallel with the newly launched Ven $\mu$ s micro-satellite (12 bands at $5 \mathrm{~m}$ ), the WorldView-3 (WV3) sensor can capture, at the daily rate, 1 panchromatic band at $0.31 \mathrm{~m}$ (hyperspatial), 8 multispectral (5 visible, VIS, and 3 near-infrared, NIR) bands at $1.24 \mathrm{~m}$, surpassing its predecessor, WorldView-2, provided with 0.46 and $1.84 \mathrm{~m}$, respectively (Collin and Planes, 2011). In addition, WV3 has the capabilities for collecting 8 short-wave infrared (SWIR) at $3.7 \mathrm{~m}$. The increase in spatial resolution improved the bathymetry extraction (Collin et al., 2017), and the addition of spectral bands meliorated the classification of minerals (Kruse and Perry, 2013) and salt marshes (Collin et al., 2018a). WV3 VIS, NIR and SWIR showed the potential to be Gram-Schmidt pansharpened (Belfiore et al., 2016), resulting in 16 spectral bands at $0.3 \mathrm{~m}$.

We hypothesize that the superspectral (16 bands), hyperspatial $(0.3 \mathrm{~m}) \mathrm{WV} 3$ can both compete with satellite hyperspectral performance and UAV spatial segmentation, for detecting complex coastal features. Classification of Moorea generic coral reefscape (Figure 1) will be examined to confront WV3 and Hyperion (30 m with 220 bands) spectral data, using artificial neural network (ANN) modelling. A spatial analysis will be tackled to compare WV3 and UAV (0.1 m with 3 bands) finescale patterns.

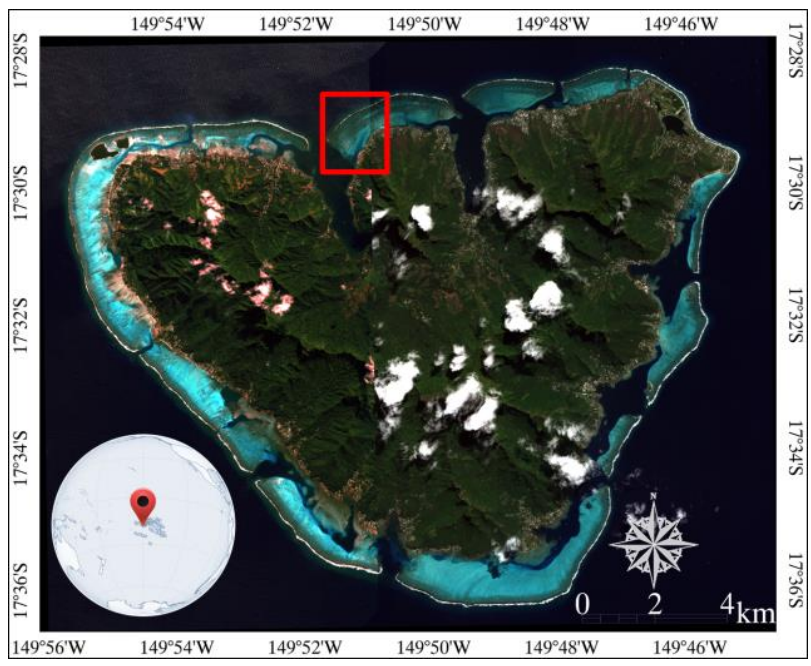

Figure 1. Natural-coloured WorldView-3 imagery of Moorea Island (French Polynesia)

\section{MATERIALS AND METHODS}

\subsection{Study site}

The study area is located on Moorea Island $\left(17^{\circ} 32^{\prime} \mathrm{S}\right.$, $149^{\circ} 50^{\prime} \mathrm{W}$ ) in South Pacific French Polynesia (Figure 1) Tahiti's sister island, 1.6-million-year-old Moorea tops at 1207 $\mathrm{m}$ and extends over $187 \mathrm{~km}^{2}$, composed of $134-\mathrm{km}^{2}$ terrestrial and 53- $\mathrm{km}^{2}$ lagoon realms (Collin et al., 2018b). Rich of its ecological land and marine diversity, as well as exposed to growing urbanization, Moorea embodies a scientific hub addressing global changes in the Anthropocene era, through a nexus of French and USA researchers (Davies et al., 2015). The area of interest stretches over $3.5 \mathrm{~km}^{2}$, and encompasses typical features of tropical reefscapes, such as outer, barrier and fringing coral reefs, lagoon with channel, and forests.

\subsection{Air truth using Unmanned Aerial Vehicle}

The variety of studied habitats has been examined using a consumer-grade UAV, DJI Mavic Pro, provided with 3 naturalcoloured bands (red-green-blue, RGB), and $0.1 \mathrm{~m}$ pixel size. Fixed at $35 \mathrm{~m}$ altitude, the automatic flight covered a $0.08-\mathrm{km}^{2}$ transect (Figure 2)

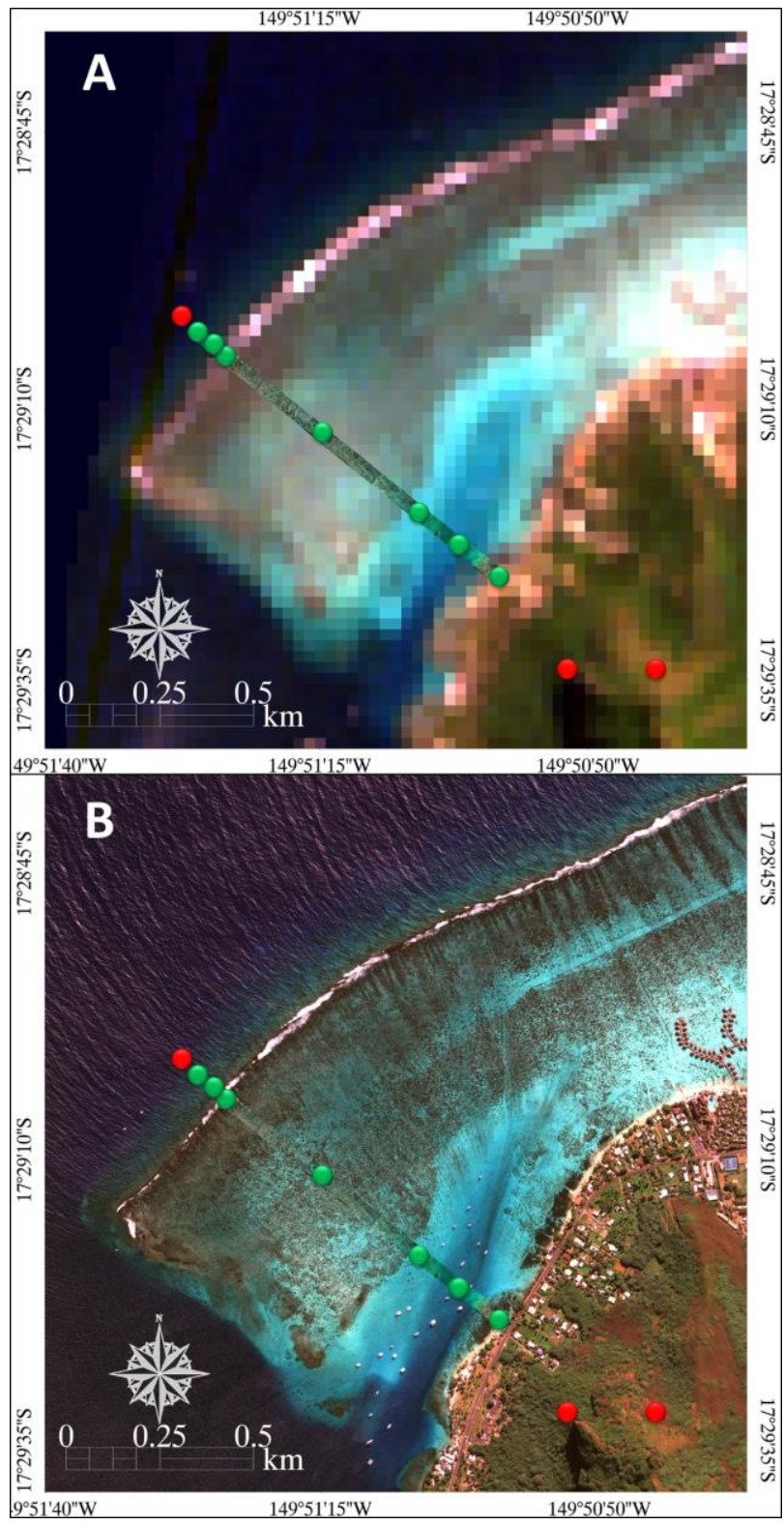

Figure 2. Natural-coloured (A) Hyperion $(30 \mathrm{~m} \times 30 \mathrm{~m})$ and $(\mathrm{B})$ WorldView-3 $(0.3 \mathrm{~m} \times 0.3 \mathrm{~m})$ imageries of the study site in Moorea Island (French Polynesia), over which is draped the unmanned aerial vehicle natural-coloured Mavic Pro imagery $(0.1 \mathrm{~m} \times 0.1 \mathrm{~m})$. Green and red points represent geolocations of the classes investigated, provided with and deprived of UAV 
A series of 86 geolocated and overlapped photographs were processed using a photogrammetric approach, resulting in a RGB orthomosaic. Given the centimetre scale, this by-product was fine enough to be considered as air-truth (Collin et al. 2018a) and discriminate 7 classes: deep outer reef, shallow outer reef, barrier reef, pavement with reef, shallow lagoon, deep lagoon and fringing reef (green disks in Figure 2). Deep ocean, wet forest and dry forest were selected directly based on the satellite imageries (red disks in Figure 2).

\subsection{Spaceborne hyperspectral Hyperion}

Launched in 2000, Hyperion imager, borne on Earth Observing1 , was the first civilian spaceborne sensor, offering 220 calibrated bands. Characterized by a low temporal resolution (200 days), Hyperion acquired imagery fitted a $30 \mathrm{~m}$ pixel size, what could be deemed as moderate spatial resolution (Table 1). Hyperion imagery was collected on May 5, 2003 at 19 h 52 min 14 s UTC. The study area (Figure $2 \mathrm{~A}$ ), composed of $65 \times 66$ pixels, was orthorectified using ground control points and bilinear resampling (datum WGS84, UTM 6 South). The radiometric correction included three steps: the factor calibration of the digital number to the top-of-atmosphere (TOA) radiance, the TOA radiance to the down-of-atmosphere (DOA) radiance considering atmosphere absorption, and the DOA radiance to the DOA reflectance, accounting for solar irradiance. Out of 220 initial bands, 167 bands were further investigated taking into account both water vapour transmission windows and overlap regions of both spectrometers.

\begin{tabular}{|l|c|c|}
\hline Specificities & \multicolumn{2}{|c|}{ Sensor } \\
\hline & Hyperion & WorldView-3 \\
Spectral range (nm) & $400-2500$ & $400-2365$ \\
Spectral resolution (nm) & 10 & 60 \\
Number of bands & 220 & 16 \\
Spatial resolution MS (m) & 30 & 1.24 \\
Spatial resolution PAN (m) & N/A & 0.31 \\
Swath width (km) & 7.5 & 13.1 \\
Time revisit (days) & 200 & 1 \\
\hline
\end{tabular}

Table 1. Hyperion and WorldView-3 specificities

\subsection{Spaceborne superspectral / hyperspatial WorldView-3}

The WV3 instrument was orbited in 2014 and is still the finest civilian VIS, NIR and SWIR sensor. The spatial enhancement of 5 VIS, 3 NIR and 8 SWIR wavebands thanks to the $0.3 \mathrm{~m}$ panchromatic resolution makes the WV3 very attractive to the scientific community tasked with submeter-, day-scale processes (Table 1). WV3 imagery, obtained on July 12, 2018 at $20 \mathrm{~h} 35$ min 39 s UTC, was subset to the study area in the form of 6243 $\times 6379$ pixels (Figure 2B). Like Hyperion, WV3 imagery was processed to be geometrically corrected, then radiometrically standardized to DOA reflectance.

\subsection{Spectral-based classification}

The first assumption of this work pointed out upfront that superspectral WV3 could classify as satisfactorily as hyperspectral Hyperion. This hypothesis has been tested across 10 coral reefscape classes, chosen for their structural, thus spectral, complexity but also their representativeness of tropical coasts. A great challenge to be overcome lay in the highly contrasted spatial resolutions of 30-m Hyperion and $0.3-\mathrm{m}$ WV3, but also 0.1-m UAV data.
2.5.1 Classes investigated: Based on UAV air truth and natural-coloured inspection, 10 spectrally-homogeneous areas were selected over Hyperion imagery (1 pixel per class), corresponding to 10000 pixels per class over WV3 imagery (Table 2). Benefiting from the correction up to the DOA reflectance level, natural-coloured patterns between Hyperion and WV3 were conspicuously recognizable across the 10 classes, irrespective of their marine or terrestrial nature (see ad hoc columns in Table 2).

\begin{tabular}{|c|c|c|c|}
\hline Class & \multicolumn{3}{|c|}{ Sensor } \\
\hline Deep Ocean & Hyperion & WV-3 & UAV \\
\hline Deep Outer Reef & & & \\
\hline Shallow Outer Reef & & & \\
\hline Barrier Reef & & & \\
\hline Pavement with Reef & & & \\
\hline Shallow Channel & & & \\
\hline Deep Channel & & & \\
\hline Fringing Reef & & & \\
\hline Wet Forest & & & \\
\hline Dry Forest & & & \\
\hline
\end{tabular}

Table 2. Hyperion, WorldView-3 and unmanned aerial vehicle Mavic Pro images of the 10 classes investigated

2.5.2 Artificial neural network modelling: The ANN, a machine learner, builds non-linear models, $h$, by minimizing least squares using a one-layer perceptron feed-forward technique, approximating the $i$ (here, $\mathrm{i}=2$ ) training responses with a constant, $k$, and Hyperion/WV3 combinations of spectral predictors, $X$, through weighted functions, $w_{i}$, adjusting neurons, $n_{i}$, that are based on the hyperbolic tangent activation function (Heermann and Khazenie, 1992):

$$
h(X)=k\left(\sum_{i} w_{i} n_{i}(X)\right)
$$

$$
\begin{array}{ll}
\text { where } & h=\text { artificial neural network model } \\
X & =\text { spectral predictors } \\
k & =\text { constant } \\
& w_{i}=\text { weighted functions } \\
& n_{i}=\text { adjusting neurons }
\end{array}
$$


Beyond overall accuracies derived from confusion matrices, a generalization of the $R^{2}$ was adopted to compare fitting performances (1000-fold validation, keeping the best model) of Hyperion/WV3 spectral combinations to categorize the 10 classes of interest. The statistic uses the $2 / n$ root of the likelihood. It ranges from the value 0 , for a model as good as a constant model, to the value 1 for a perfect model.

\subsection{Spatial-based segmentation}

In addition to its superspectral specificities, WV3 has the potential to provide information at $0.3 \mathrm{~m}$, leading the civilian spaceborne optical imagery. The second assumption of this research relied on WV3 hyperspatial capacity to discriminate complex spatial patterns as suitable as centimetre-scale UAV. This conjecture has been evaluated by segmenting both imageries using the edge algorithm (objects with sharp edges), and the full lambda schedule for merging small objects within larger, textured ones. The selected texture kernel size has been fixed at 3 pixels.

\section{RESULTS AND DISCUSSION}

Our results, firstly, focused on the bridge between spaceborne hyperspectral Hyperion and superspectral WV3, and secondly dealt with the linkage between hyperspatial WV3 and UAV.

\subsection{Hyperion and WV3 spectral classification}

Prior to show ANN results of the classification, DOA reflectances of the 8 marine and 2 land classes were plotted for Hyperion and WV3 (Figures 3 and 4).

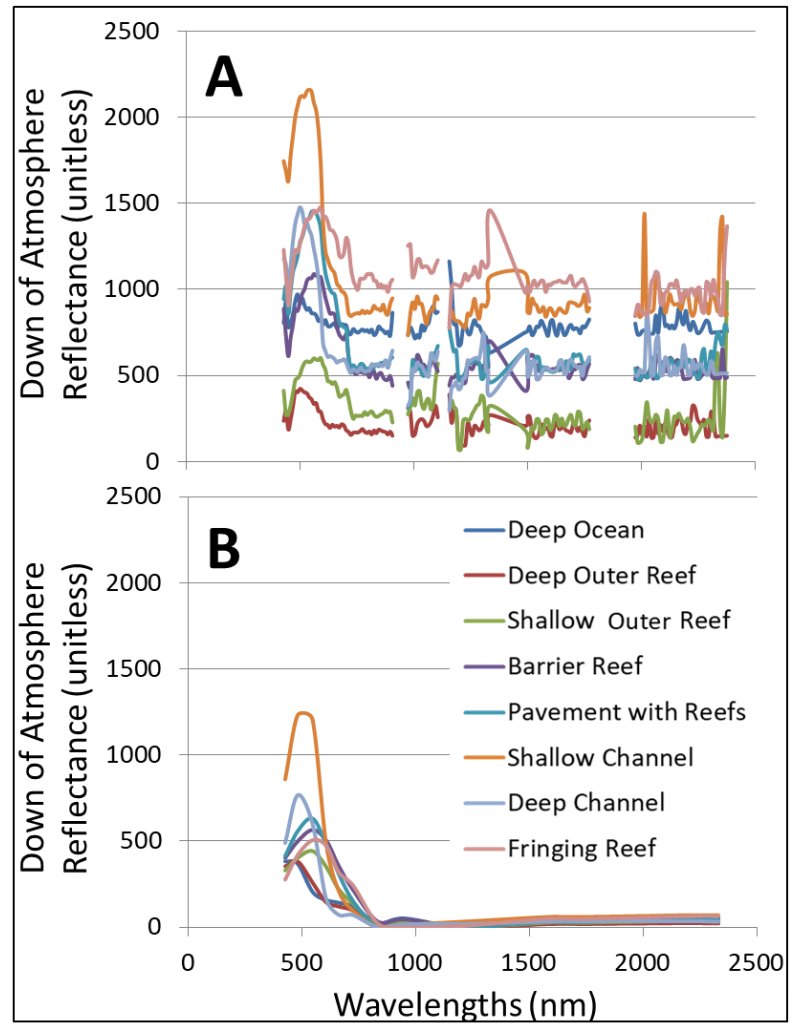

Figure 3. Hyperion spectral signatures of the 10 classes (A: 8 marine, B: 2 terrestrial). 167 bands out of 220 were operable

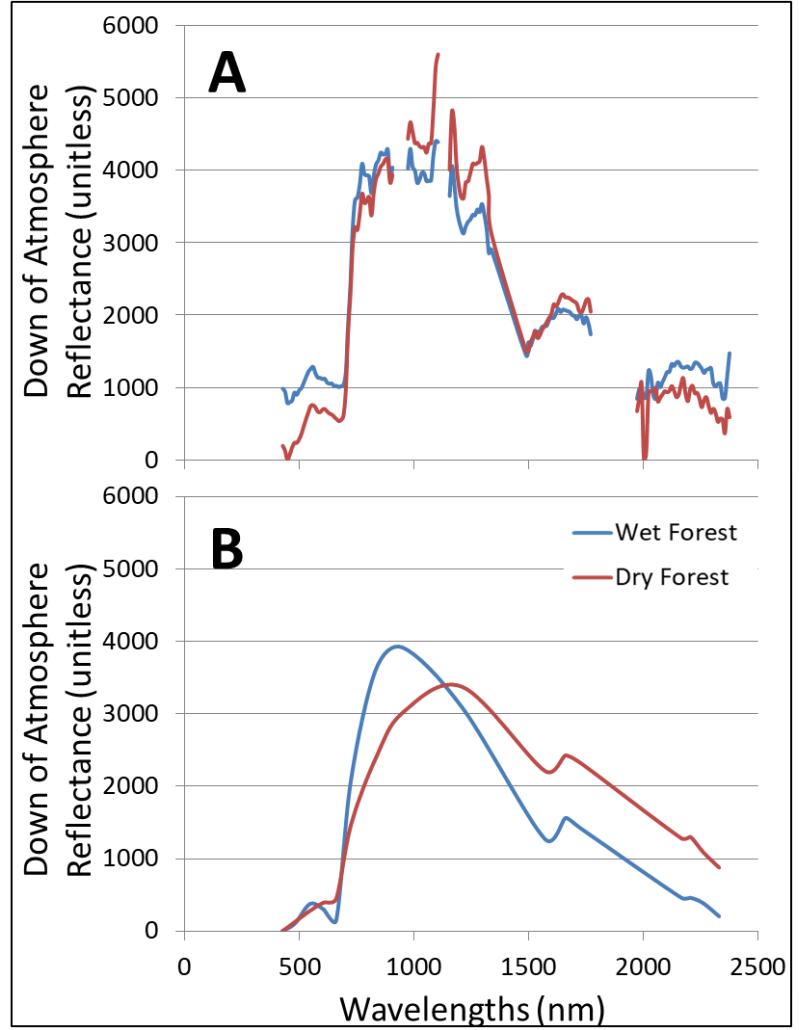

Figure 4. WorldView-3 spectral signatures of the 10 classes (A:

8 marine, B: 2 terrestrial). 16 bands were operable

Overall, Hyperion DOA reflectance was higher than WV3 one, and classes seemed more contrasted for Hyperion NIR and SWIR. Common spectral patterns were constant in the VIS spectrum: highest reflectance for shallow channel, followed by deep channel, pavement with reef, barrier reef, shallow outer reef, deep outer reef. However, Fringing reef, deep ocean and dry forest appeared brighter, relatively to other classes, for Hyperion compared to WV3. Discrepancies between both sensors might be explained by the spatial Hyperion information, based on a single $30-\mathrm{m}$ pixel (Table 2), over-reflecting water classes within absorbing NIR and SWIR, due to sun glint integration in the coarse pixel.

Results of the ANN modelling, classifying the 10 classes based on combinations of Hyperion and WV3 spectral wavebands, were significant (Figure 5). RGB (3 bands), RGBNIR (4 bands), RGB-Coastal-yellow (5 bands) and RGBNIRs ( 8 bands) classifications showed greater performances for Hyperion than WV3 (0.06 difference in $R^{2}$ ). The combination, including 16 WV3 bands, and corresponding 16 Hyperion bands, was still better for Hyperion, but with a reduction in deviation $(0.04$ difference in $R^{2}$ ), due to the rise trend of WV3 and a slight decrease of Hyperion. The latter sensor's score further declined when all 167 bands were integrated into ANN modelling, making the 16-band WV3 combination a better predictor than Hyperion. Hyperion counter-performance might be justified by the spectro-statistical noise conveyed by too many bands, thus the need for dimensionality reduction (Keller et al., 2016). 


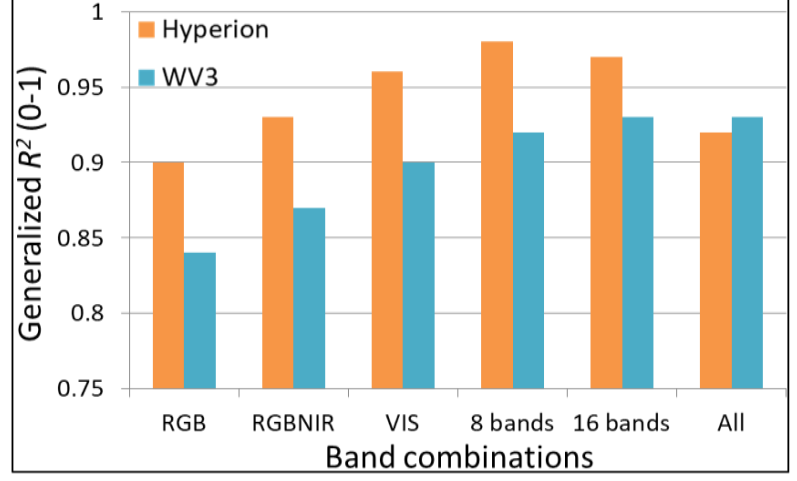

Figure 5. Hyperion and WorldView-3 comparison of the classification performances using one-layered artificial neural networks for the 10 classes investigated

\subsection{WV3 and UAV spatial segmentation}

Comparisons of segmentation applied to WV3 and UAV subsets were informative (Figure 6).
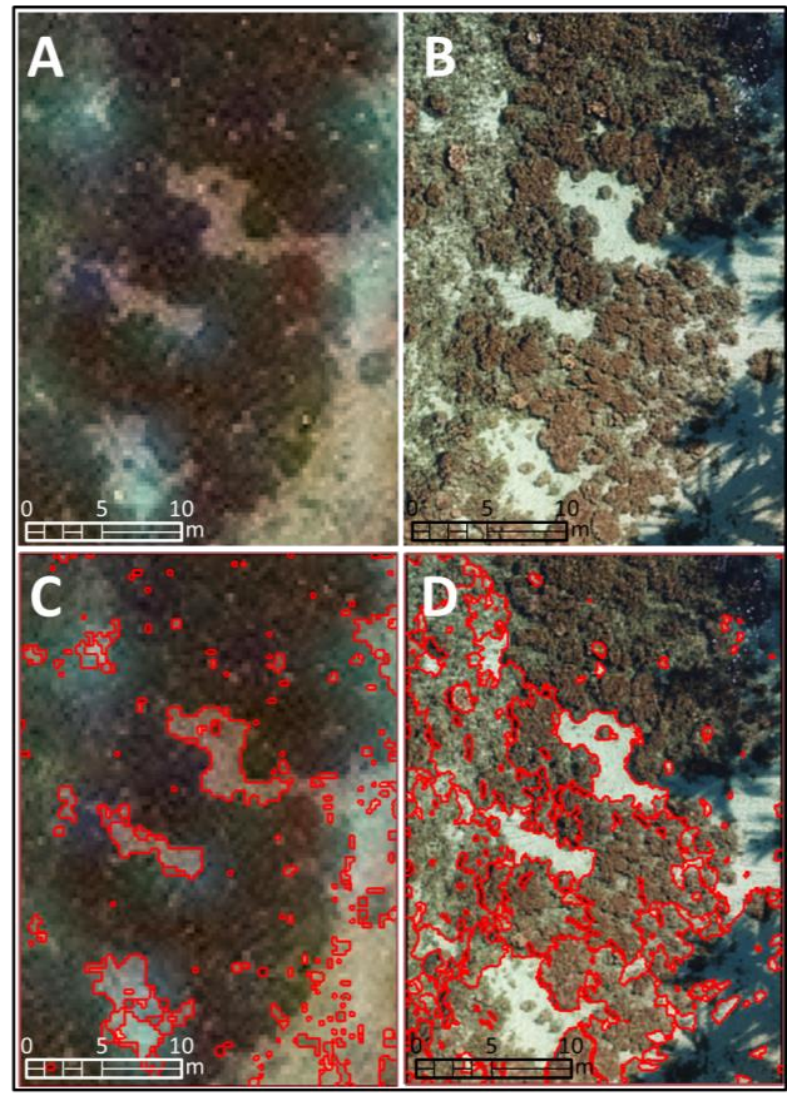

Figure 6. Comparison of a fringing reef subset of naturalcoloured (A) WorldView-3 (0.3 m pixel size) and (B) UAV (0.1 $\mathrm{m}$ pixel size), as well as segmented (C) WorldView-3 and (D) UAV imageries

Despite a 3-fold factor separating WV3 and UAV spatial resolution, the segmentation processing, relying on edge algorithm and full lambda schedule fusion, produced similar outcomes in a qualitative perspective: pavement/sand patches over WV3 imagery were as successfully delineated as UAV one within the fringing reef matrix. The main difference resided in the refined delimitation of small pavement/sand patches, visible on UAV, and barely detected on WV3. The segmentation could be enhanced using the intensity algorithm, leveraging $16 \mathrm{WV} 3$ information, compared to $3 \mathrm{UAV}$ one. Beyond the physical limitations of pixel size, WV3 pansharpening procedure, producing halo-like artefacts, might be improved using a dedicated hypersharpening technique (Kwan et al., 2017).

\section{CONCLUSIONS}

Complex scenes, such as coastal tropical systems, require sensors provided with high spectral, spatial and temporal resolution. We propose here to bridge hyperspectral $30-\mathrm{m}$ spaceborne instruments, such as Hyperion, and hyperspatial 3band UAV, such as DJI Mavic Pro. The 0.3-m WV3 sensor has demonstrated that its 16-band combination rivalled 167-band Hyperion for classifying 10 classes using ANN modelling, while competing with 0.1-m UAV for segmenting fringing coral reefs. Conciliating spectral and spatial requirements needed for coasts, the WV3 benefits from an hypertemporal resolution, namely a daily revisit, as good as UAV's one.

\section{ACKNOWLEDGEMENTS}

Fieldwork and UAV survey was carried out into the "Reef I Were" project supported by the CNRS PEPS TOHMIS, and spaceborne imagery was delivered by DigitalGlobe Foundation.

\section{REFERENCES}

Anne, N.J., Abd-Elrahman, A.H., Lewis, D.B., Hewitt, N.A., 2014. Modeling soil parameters using hyperspectral image reflectance in subtropical coastal wetlands. International Journal of Applied Earth Observation and Geoinformation, 33, 47-56.

Belfiore, O.R., Meneghini, C., Parente, C., Santamaria, R., 2016. Application of different Pan-sharpening methods on WorldView-3 images. ARPN-JEAS, 11, 490-496.

Brando, V.E., Dekker, A.G, 2003. Satellite hyperspectral remote sensing for estimating estuarine and coastal water quality. IEEE transactions on geoscience and remote sensing, 41(6), 1378-1387.

Collin, A., Archambault, P., Planes, S., 2013. Bridging ridgeto-reef patches: Seamless classification of the coast using very high resolution satellite. Remote Sensing, 5(7), 3583-3610.

Collin, A., Etienne, S,. Feunteun, E., 2017. VHR coastal bathymetry using WorldView-3: colour versus learner. Remote Sensing Letters, 8(11), 1072-1081.

Collin, A., Hench, J. L., Pastol, Y., Planes, S., Thiault, L., Schmitt, R. J., ... , Troyer, M., 2018b. High resolution topobathymetry using a Pleiades-1 triplet: Moorea Island in 3D. Remote sensing of environment, 208, 109-119.

Collin, A., Lambert, N., Etienne, S., 2018a. Satellite-based salt marsh elevation, vegetation height, and species composition mapping using the superspectral WorldView-3 imagery. International Journal of Remote Sensing, 39(17), 5619-5637.

Collin, A., Nadaoka, K., Nakamura, T., 2014. Mapping VHR water depth, seabed and land cover using Google Earth data. ISPRS International Journal of Geo-Information, 3(4), 11571179. 
Collin, A., Planes, S., 2011. What is the value added of 4 bands within the submetric remote sensing of tropical coastscape? Quickbird-2 vs WorldView-2. In IEEE International Geoscience and Remote Sensing Symposium, 2165-2168.

Davies, N., Field, D., Gavaghan, D., Holbrook, S. J., Planes, S., Troyer, M., ..., Zettler, L.A., 2016. Simulating social-ecological systems: the Island Digital Ecosystem Avatars (IDEA) consortium. GigaScience, 5(1), 14.

Dierssen, H.M., Chlus, A., Russell, B., 2015. Hyperspectral discrimination of floating mats of seagrass wrack and the macroalgae Sargassum in coastal waters of Greater Florida Bay using airborne remote sensing. Remote Sensing of Environment, $167,247-258$

Heermann, P.D., Khazenie, N., 1992. Classification of multispectral remote sensing data using a back-propagation neural network. IEEE Transactions on Geoscience and Remote Sensing, 30(1), 81-88.

Honkavaara, E., Rosnell, T., Oliveira, R., Tommaselli, A., 2017. Band registration of tuneable frame format hyperspectral UAV imagers in complex scenes. ISPRS Journal of Photogrammetry and Remote Sensing, 134, 96-109.

Jones, T.G., Coops, N.C., Sharma, T., 2010. Assessing the utility of airborne hyperspectral and LiDAR data for species distribution mapping in the coastal Pacific Northwest, Canada. Remote Sensing of Environment, 114(12), 2841-2852.

Keller, S., Braun, A. C., Hinz, S., Weinmann, M., 2016. Investigation of the impact of dimensionality reduction and feature selection on the classification of hyperspectral EnMAP data. In 8th Workshop on Hyperspectral Image and Signal Processing: Evolution in Remote Sensing (WHISPERS), 1-5.

Keller, S., Maier, P., Riese, F., Norra, S., Holbach, A., Börsig, N., et al., 2018. Hyperspectral Data and Machine Learning for Estimating CDOM, Chlorophyll a, Diatoms, Green Algae and Turbidity. International journal of environmental research and public health, 15(9), 1881.

Kruse, F., Perry, S., 2013. Mineral mapping using simulated Worldview-3 short-wave-infrared imagery. Remote Sensing, 5(6), 2688-2703.

Kutser, T., Miller, I., Jupp, D.L., 2006. Mapping coral reef benthic substrates using hyperspectral space-borne images and spectral libraries. Estuarine, Coastal and Shelf Science, 70(3), 449-460.

Kwan, C., Budavari, B., Bovik, A.C., Marchisio, G., 2017. Blind quality assessment of fused worldview-3 images by using the combinations of pansharpening and hypersharpening paradigms. IEEE Geoscience and Remote Sensing Letters, 14(10), 1835-1839.

Lucke, R.L., Corson, M., McGlothlin, N.R., Butcher, S.D., Wood, D.L., Korwan, D.R., ..., Chen, D.T., 2011. Hyperspectral Imager for the Coastal Ocean: instrument description and first images. Applied optics, 50(11), 1501-1516.

Müller, R., Bachmann, M., Makasy, C., De Miguel, A., Müller, A., Neumann, A., ..., Walzel, T., 2010. The processing chain and $\mathrm{Cal} / \mathrm{Val}$ operations of the future hyperspectral satellite mission EnMAP. In 2010 IEEE Aerospace Conference, 1-9.
Peneva, E., Griffith, J.A., Carter, G.A., 2008. Seagrass mapping in the northern Gulf of Mexico using airborne hyperspectral imagery: a comparison of classification methods. Journal of Coastal Research, 24(4), 850-856.

Pengra, B.W., Johnston, C.A., Loveland, T. R., 2007. Mapping an invasive plant, Phragmites australis, in coastal wetlands using the EO-1 Hyperion hyperspectral sensor. Remote Sensing of Environment, 108(1), 74-81.

Tuia, D., Flamary, R., Courty, N., 2015. Multiclass feature learning for hyperspectral image classification: Sparse and hierarchical solutions. ISPRS Journal of Photogrammetry and Remote Sensing, 105, 272-285.

Van Mol, B., Ruddick, K., 2004. The Compact High Resolution Imaging Spectrometer (CHRIS): the future of hyperspectral satellite sensors. Imagery of Oostende coastal and inland waters. In Proceedings of the Airborne Imaging Spectroscopy workshop, Brugge.

Weinmann, M., Maier, P. M., Florath, J., Weidner, U., 2018. Investigations on the potential of hyperspectral and Sentinel-2 data for land cover/land use classification. ISPRS Annals of Photogrammetry, Remote Sensing \& Spatial Information Sciences, 4(1).

Zhou, H., Mao, Z., Wang, D., 2005. Classification of coastal areas by airborne hyperspectral image. Optical Technologies for Atmospheric, Ocean, and Environmental Studies, 5832, 471477. 